\title{
Cryotherapy and laser treatment for acute retinopathy of prematurity: refractive outcomes, a longitudinal study
}

\author{
Fiona Laws, David Laws, David Clark
}

\begin{abstract}
Background-Infants who require treatment for threshold retinopathy of prematurity are at increased risk of developing refractive errors. Following the introduction of laser treatment for threshold disease, the clinical impression was that the degree of myopia was reduced compared with cryotherapy.

Methods-A longitudinal study was carried out of refractive error at 3 and 12 months in 19 patients undergoing cryotherapy and 15 patients undergoing laser treatment.

Results-At 3 months the median spherical equivalent refractive error in the right eye was -3.25 dioptres after cryotherapy and +0.25 dioptres after laser therapy (similar results left eye). The median spherical equivalent refractive error in the right eye at 12 months was $\mathbf{- 5 . 2 5}$ dioptres following cryotherapy and $\mathbf{- 0 . 5 0}$ dioptres after laser (similar results left eye). There was a statistically significant difference in median spherical refractive error between the therapies at 3 months and 12 months $(p<0.05$ Wilcoxon rank sum) in both eyes.

Conclusion-Laser therapy is associated with lower degrees of myopia during the first year of life, which is clinically significant in terms of visual performance and development.

(Br F Ophthalmol 1997;81:12-15)
\end{abstract}

Refractive errors, including myopia, are well recognised following premature birth. ${ }^{1-6}$ It was our clinical impression that infants undergoing cryotherapy for threshold retinopathy of prematurity (ROP) were at increased risk of developing this complication.

The degree of myopia appeared less than that recorded after cryotherapy following the advent of laser as the first line treatment at this unit in 1992

Algawi et $a l^{7}$ described 40 eyes of infants in a cross sectional study and showed that eyes treated with diode laser photocoagulation developed significantly less myopia than those treated with cryotherapy.

We undertook a longitudinal study to investigate the change in the refractive errors in 62 eyes of infants who attained threshold disease and underwent either cryotherapy or laser treatment.

\section{Methods}

Infants were identified who had undergone treatment for threshold ROP at the regional neonatal intensive care unit in Merseyside since commencement of the ROP screening service and who had survived more than 1 year.

Twelve cryotherapy treated and eight laser treated infants were nursed in Liverpool and seven cryotherapy and seven laser treated infants were referred for treatment alone. This latter group included two infants from outside the Merseyside boundary.

One observer (DC) classified the disease severity in all cases using the international classification of acute disease. ${ }^{8}$ Infants who had gone on to develop stage 4 or 5 disease by 3 months were excluded from the study. Two infants with zone I disease treated with cryotherapy developed stage 5 in one eye. The successfully treated eyes were included in the study.

Up to 1992 those who developed threshold disease were treated using cryotherapy applied over the non-vascularised retina. Infants requiring treatment after 1992 received either indirect argon or diode laser to the nonvascularised retina. The average postconceptional age at treatment for both cryotherapy and laser was 38 weeks, the ranges for cryotherapy were 34-43 weeks and for laser treatment 34-41 weeks. The treatments were carried out between 1989 and 1993 by one ophthalmologist (DC).

Since the commencement of ROP screening at this centre data on refractive outcome of infants with acute disease have been collected in a standardised fashion at 3 months and 1 year corrected age using the same protocol. One optometrist was principally involved in the refraction of all but the 3 month data on six infants. Cycloplegic streak retinoscopy was performed at both visits. Cycloplegia was obtained using cyclopentolate $0.5 \%$ at the 3 month visit, to reduce the risk of side effects in the smaller children, ${ }^{9}$ and cyclopentolate $1 \%$ at the 1 year visit. Refraction was performed using handheld lenses in front of awake infants. The sphere, positive cylinder, and axis were recorded and the equivalent sphere was calculated from the formula; spherical equivalent $(\mathrm{SE})=( \pm$ sphere $)+0.5($ cylinder $) .{ }^{10}$

In a previous study on this cohort more infants had posterior disease in the cryotherapy group. To avoid bias due to disease severity, a subgroup of infants with anterior disease
Accepted for publication 1 August 1996 
Table 1 Treatment, birth weight, and gestation of study infants

\begin{tabular}{lrr}
\hline & Cryotherapy & Laser \\
\hline Number & 18 & \\
Right & 16 & 13 \\
Left & 780 & 15 \\
Median birth weight (g) & 26 & 800 \\
Median gestation (weeks) & 25 \\
\hline
\end{tabular}

(anterior or mid zone II) was analysed separately. Our previously described definition of anterior (anterior or mid zone II) or posterior (posterior zone II or zone I) disease was used. ${ }^{11}$

The difference in refractive outcome of the two treatments was assessed using medians and the Wilcoxon rank sum test for non-paired data on the spherical equivalents, as the data were not normally distributed. The prevalence and magnitude of astigmatism and anisometropia were also examined in the two groups. Anisometropia was analysed separately in a subgroup of four infants treated in one eye only (two cryotherapy and two laser). As the ROP status of fellow eyes is not completely independent, ${ }^{12}$ right and left eyes were analysed separately to avoid individual bias.

\section{Results}

Thirty four infants were enrolled into the study -30 had bilateral treatment, four had asymmetric disease and were treated in one eye (two right and two left). Nineteen infants underwent cryotherapy and 15 laser treatment. The birth weight and gestational age of the two groups were similar (Table 1). Twenty two eyes in the cryotherapy group and 22 eyes in the laser group had anterior disease, the mean age at treatment was 38.8 weeks post-menstrual

Table 2 Median refractive outcome in dioptres (D) for both eyes at 3 and 12 months following cryotherapy or laser

\begin{tabular}{|c|c|c|c|}
\hline & & Cryotherapy & Laser \\
\hline Three months (range) & $\begin{array}{l}\text { Right } \\
\text { Left }\end{array}$ & $\begin{array}{l}-3.25(-13.50 \text { to }+2.50) \\
-2.00(-8.00 \text { to }+3.25)\end{array}$ & $\begin{array}{l}+0.25(\mathrm{p}=0.01)(-11.00 \text { to }+5.00) \\
+0.75(\mathrm{p}=0.01)(-4.00 \text { to }+4.88)\end{array}$ \\
\hline Twelve months (range) & $\begin{array}{l}\text { Right } \\
\text { Left }\end{array}$ & $\begin{array}{l}-5.25(-23.75 \text { to }+0.75) \\
-6.00(-15.25 \text { to }+0.88)\end{array}$ & $\begin{array}{l}-0.50(\mathrm{p}=0.05)(-13.00 \text { to }+3.00) \\
-0.375(\mathrm{p}=0.03)(-12.75 \text { to }+2.625)\end{array}$ \\
\hline
\end{tabular}

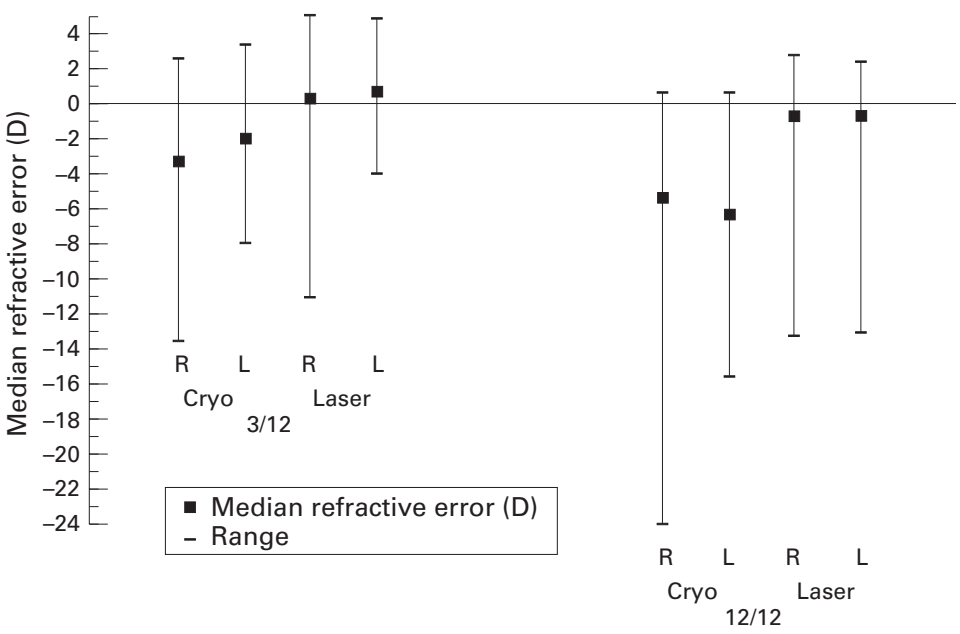

Figure 1 Median refractive outcome and ranges (D) for both eyes at 3 and 12 months following cryotherapy or laser. age (PMA) for cryotherapy and 38.7 weeks PMA for laser. Both anterior disease groups had similar clock hours of stage 3 .

There were more cases of posterior disease in the cryotherapy group than the laser group, 12 and six eyes respectively.

At 3 months corrected age and at 1 year the cryotherapy group had a statistically significant higher degree of myopia in both eyes $(p<0.05$ at 3 and 12 months, Table 2). There was a wide range of refractive errors for both groups (Fig 1).

Statistical comparison of myopia in those with anterior disease versus mode of treatment was significant at 12 months for both eyes $(\mathrm{p}<$ 0.05) with more myopia in the cryotherapy group. The median myopic progression was $3.00 \mathrm{D}$ right and $3.75 \mathrm{D}$ left (SE) for the cryotherapy group and $1.75 \mathrm{D}$ right and $1.25 \mathrm{D}$ left (SE) for laser (Table 3). Statistical comparison of the refractive outcome between posterior disease and mode of treatment was not possible because of small numbers but there was a trend of more myopia in those treated with cryotherapy. Comparison of the refractive outcome between anterior and posterior disease was similarity not possible; however, the trend was towards higher myopia in those with posterior disease.

Anisometropia was not significantly different in magnitude between the two groups. The mean level of anisometropia at 3 months and 1 year for both groups was around 1.5 dioptres $\mathrm{SE}$, the maximum being 8.75 dioptres in an infant with significant macular dragging.

Of the four infants undergoing treatment in one eye only, there was a mean level of anisometropia of $1.78 \mathrm{D}$ at 3 months and 3.90 $\mathrm{D}$ at 12 months.

Astigmatism of $>1.00 \mathrm{D}$ is shown in Table 4. The magnitude of astigmatism was higher in the infants treated with cryotherapy at both ages with both groups showing a reduction at 12 months. The axis of astigmatism in all groups at both ages was most frequently at 90 degrees. This was not statistically significant for either group.

\section{Discussion}

This study has demonstrated that cryotherapy for threshold ROP is associated with a greater degree of myopia than laser therapy in the first year of life. The myopia increased at a greater rate in the cryotherapy treated infants over the 9 month study period. Previous reports on refractive data of full term and premature infants have shown a wide range of refractive error in early life. ${ }^{13}$ The majority of the refractive errors in this study at 3 months in both treatment groups would fall within this 'normal' range. However, the normal process of emmetropisation commonly fails to occur in threshold treated infants, especially those treated with cryotherapy. The subsequent progression of refractive error in these children will lead to increasing visual handicap. Although the median refractive error for the laser treated group was small at 12 months $(-0.375$ DS) there was a large range of errors in both groups. 
Table 3 Median refractive outcome and myopic progression in dioptres (D) for eyes with anterior disease at 3 and 12 months following cryotherapy or laser

\begin{tabular}{llll}
\hline & & Cryotherapy & Laser \\
\hline Three months (range) & Right & $-4.00(-11.00$ to +2.50$)$ & $+0.25(\mathrm{p}=0.08)(-11.00$ to +5.00$)$ \\
& Left & $-2.00(-8.00$ to +2.5$)$ & $+0.50(\mathrm{p}=0.08)(-3.00$ to +4.88$)$ \\
Twelve months (range) & Right & $-5.25(-14$ to +0.875$)$ & $-0.50(\mathrm{p}=0.04)(-13.00$ to +2.75$)$ \\
& Left & $-5.25(-13.00$ to +0.88$)$ & $-0.25(\mathrm{p}=0.01)(-12.75$ to +2.625$)$ \\
Progression of myopia (range) & Right & $-3.00(0.25$ to -8.875$)$ & $-1.75(1.00$ to -7.125$)$ \\
& Left & $-3.75(0.125$ to -6.75$)$ & $-1.25(2.00$ to -7.875$)$ \\
\hline
\end{tabular}

Table 4 Prevalence of astigmatism with means and axes for cylindrical error $>1.00$ at 3 and 12 months following cryotherapy or laser

\begin{tabular}{|c|c|c|c|c|}
\hline & \multicolumn{2}{|l|}{ Cryotherapy $(n=34)$} & \multicolumn{2}{|l|}{ Laser $(n=28)$} \\
\hline & $3 / 12$ & $12 / 12$ & $3 / 12$ & $12 / 12$ \\
\hline \multicolumn{5}{|l|}{ Astigmatism (D) } \\
\hline$>1$ & $13(38 \%)$ & $12(35 \%)$ & $9(32 \%)$ & $14(50 \%)$ \\
\hline Mean (D) (range) & $2.37(1.25$ to 5.00$)$ & $2.04(1.25$ to 4.50$)$ & $2.167(1.23$ to 3.5$)$ & $1.60(1.25$ to 3.00$)$ \\
\hline \multicolumn{5}{|l|}{ Axis } \\
\hline 90 & 8 & 7 & 5 & 6 \\
\hline 180 & 3 & 4 & 3 & 5 \\
\hline Oblique & 2 & 1 & 1 & 3 \\
\hline
\end{tabular}

There was no difference in the level of anisometropia between cryotherapy and laser groups, but the magnitude in some patients may be of clinical significance. The maximum value was $8.75 \mathrm{D}$ in one of the laser treated infants. The more myopic eye had macula dragging. Anisometropia would not be unexpected in cases with asymmetric disease; four infants with asymmetric ROP had treatment in one eye only, the fellow eye developed stage 2 disease. We found clinically significant levels of anisometropia of $3.8 \mathrm{D}$ at 1 year. However, it is not possible to say whether the anisometropia is due to a treatment effect or unequal disease severity. Previously published data on four infants treated in one eye only did not show anisometropia and inferred that treatment did not affect refractive outcome. ${ }^{14}$

Over $30 \%$ of eyes in this study had astigmatism of $>1.00 \mathrm{D}$. There was a trend to higher levels of astigmatism in the cryotherapy treated infants but this did not reach statistical significance, even when right and left eyes were analysed together. The incidence of astigmatism in full term infants has been reported as $19 \% .{ }^{15}$ In premature infants, however, the incidence of astigmatism $>1.00 \mathrm{D}$ occurs in more than $70 \% .{ }^{16}$ Laws et al found an increasing magnitude of astigmatism with increasing stage of ROP, though no infant reached stage 3 threshold disease. The mechanism of astigmatic development is probably multifactorial, though treatment modality may have a compounding influence.

IS THE MYOPIA DUE TO THE DISEASE OR THE TREATMENT?

Previous studies have clearly demonstrated that myopia is associated with prematurity and low birth weight in infants who do not receive treatment for retinopathy. ${ }^{15616-19}$ Quinn reported a higher incidence of myopia in infants with posterior pole residua of regressed ROP and this may explain the magnitude of myopic anisometropia in the infant with macular ectopia. ${ }^{20}$ The CryoROP study demonstrated more myopia in the treated versus untreated group.
However, in the latter study the higher incidence of unfavourable results (that is, retinal detachments) in the untreated group may have biased the results as those eyes were not available for refraction. ${ }^{2122}$

It is not possible to say if the myopia observed in the laser group was more than expected for this degree of retinopathy as it would now be unethical to obtain a matched group without treatment. However, we have shown a statistically significant difference between the two modalities of treatment in those eyes with anterior disease in whom the disease severity and location was the same (Table 3). The success of treatment was also comparable, two failures in the cryotherapy treated group and one in the laser group. Cryotherapy has been suggested as a contributing factor in the development of myopia by other workers and our results support this argument. ${ }^{1423}$

Disease location, whether anterior or posterior, appeared to have some influence on the incidence of myopia. The more posterior the disease the more severe the myopia and the trend was for more myopia in those treated with cryotherapy. There were more eyes with posterior disease in the cryotherapy treated group which may have influenced these results. Unfortunately the numbers were too small to analyse the posterior treated groups separately.

It has also been suggested that the timing of treatment may influence the degree of myopia with more advanced fibrovascular proliferation present if treatment is late. ${ }^{24}$ In our study the two groups with anterior disease were treated at the same mean post-menstrual age, 38 weeks, so this was not a factor influencing the results. Algawi et al also found more myopia in cryotherapy treated eyes than laser though the timing of treatment and locality of the disease was not discussed.

The observed difference in refractive outcome between the two groups may be attributable to the effect of cryotherapy applied to the developing sclera at an actively growing site. ${ }^{25}$ Laser treatment administered through the 
pupil is less destructive than cryotherapy though there may be some thermal effect on the inner sclera if high energy burns are used. ${ }^{26-28}$

In summary, this study confirms an earlier report of more myopia in cryotherapy treated infants. Importantly we have corrected for disease severity and location. Furthermore, we have shown that the rate of progression of myopia is greater in those infants treated with cryotherapy. The influence of treatment should be considered when choosing the treatment modality in the management of threshold disease.

The aetiology of myopia in ROP is still unknown. Further research into this interesting subject will be necessary before the cause is fully understood.

1 Gordon RA, Donzis PA. Myopia associated with retinopathy of prematurity. Ophthalmology 1986;93:1593-8.

2 Hungerford J, Stewart A, Hope P. Ocular sequelae of preterm birth and their relation to ultrasound evidence of cerebral damage. Br f Ophthalmol 1986;70:463-8.

3 Keith CG, Kitchen WH. Ocular morbidity in infants of very low birthweight. Br $\mathcal{F}$ Ophthalmol 1983;67:302-5.

4 Koraszewska MB, Samochowiec DE, Pieczara E, Papiez M. Myopia as a complication of retinopathy of prematurity] Klin Oczna 1993;95(9-10):339-42.

5 Laws D, Shaw DE, Robinson J, Jones HS, Ng YK, Fielder AR. Retinopathy of prematurity: a prospective study. Review at six months. Eye 1992;6:477-83.

6 Nissenkorn I, Yassur Y, Mashkowski D, Sherf I, Ben-Sira I. Myopia in premature babies with and without retinopathy of prematurity. Br $\mathcal{F}$ Ophthalmol 1983;67:170-3.

7 Algawi K, Goggin M, O'Keefe M. Refractive outcome following diode laser versus cryotherapy for eyes with following diode laser versus cryotherapy for eyes with
retinopathy of prematurity. $\mathrm{Br} \mathcal{F}$ Ophthalmol 1994;78: retinopathy

8 Committee for the Classification of Retinopathy of Prematurity. An international classification of retinopathy of prematurity. Arch Ophthalmol 1984;102:1130-3.

9 Moore A. Refraction of infants and young children. In Taylor D, ed. Pediatric ophthalmology. Oxford: Blackwell Scientific Publications, 1990:65-70.

10 Lavery J, Gibson J, Shaw D, Rosenthal A. Refraction and refractive errors in an elderly population. Ophthalmol Physiol Opt 1988;8:394-6.
11 Noonan CP, Clark DI. Trends in management of stage 3 retinopathy of prematurity. $\mathrm{Br} \mathcal{F}$ Ophthalmol 1996;80: retinopathy $278-81$.

12 Quinn G, Dobson V, Biglan A, Evans J, Plotsky D, Hardy RJ. Correlation of retinopathy of prematurity in fellow eyes in the cryotherapy for retinopathy of prematurity study. Arch Ophthalmol 1995;113:469-73.

13 Banks MS. Infant refraction and accomodation. Int Ophthalmol Clin 1980;20(1):205-32.

14 Seiberth V, Knorz MC, Trinkmann R. Refractive errors after cryotherapy in retinopathy of prematurity. Ophthalmologica 1990;201:5-8.

15 Fulton AB, Dobson V, Salem D, Mar C, Petersen RA, Hansen RA. Cycloplegic refractions in infants and young children. Am f Ophthalmol 1980;90:239-47.

16 Dobson V, Fulton AB, Manning K, Salem D, Petersen RA. Cycloplegic refractions of premature infants. $A m \quad \mathcal{F}$ Ophthalmol 1981;91:490-5.

17 Fletcher MC, Brandon S. Myopia of prematurity. Am $\mathcal{F}$ Ophthalmol 1955;40:474-81.

18 Scharf J, Zoniss S, Zeltrer M. Refraction in premature babies. A prospective study. I Pediatr Ophthalmol 1978;15: $48-50$.

19 Shapiro A, Yanko L, Nawratzki J. Refractive power of premature children at infancy and early childhood. Am $\mathcal{F}$ Ophthalmol 1980;90:234-8.

20 Quinn GE, Dobson V, Repka MX, Reynolds J, Kivlin J, Davis B, et al. Development of myopia in infants with birth weights less than 1251 grams. Ophthalmology1992;99:32940

21 Cryotherapy for Retinopathy of Prematurity Cooperative Group. Multicenter trial of cryotherapy for retinopathy of prematurity. Three-month outcome. Cryotherapy for Retinopathy of Prematurity Cooperative Group [see comments]. Arch Ophthalmol 1990;108(2):195-204.

22 Cryotherapy for Retinopathy of Prematurity Cooperative Group. Multicentre trial of cryotherapy for retinopathy of prematurity. 31/2 year outcome structure and function. Arch Ophthalmol 1993;111:339-44.

23 Gordon RA, Donzis PB. Myopia associated with retinopathy of prematurity. Ophthalmology 1986;93:1593-8.

24 Schulenburg W, Acheson J. Cryosurgery for acute retinopathy of prematurity: factors associated with treatment pathy of prematurity: factors associated
success and failure. Eye 1992;6:215-20.

25 Fielder AR. Cryotherapy of retinopathy of prematurity. In: Fielder AR. Cryotherapy of retinopathy of prematurity. In: Edinburgh: Churchill Livingstone, 1992:129-48.

26 Nissenkorn I, Kremer I, Ben Sira I, Cohen S, Garner S. A clinicopathological case of retinopathy of prematurity (ROP) teated by cryopexy. Br f Ophthalmol 1984;68:36-41.

27 Wallow I, Sponsel W, Stevens T. Clinicopathologic correlation of diode laser burns in monkeys. Arch Ophthalmol 1991;109:648-53.

28 Benner JD, Huang M, Morse L, Hijelmeland L, Landers M. Comparison of photocoagulation of argon, crypton and Ophthalmology 1992;99:1554-63. 